03

\title{
Исследование метода оптимизации формы тела для уменьшения силы аэродинамического сопротивления \\ в потоке газа
}

\author{
(c) Н.Н. Чернов, А.В. Палий ", А.В. Саенко, А.М. Маевский
}

Южный федеральный университет, Институт нанотехнологий, электроники и приборостроения, Таганрог, Россия

๑E-mail: avpaliy@sfedu.ru

Поступило в Редакцию 18 апреля 2017 г.

Представлены результаты исследования обтекания тел различных геометрических форм в аэродинамическом потоке с целью сравнения величин сил аэродинамического сопротивления оптимизированной формы тела на основе предложенного авторами метода с аналогичными величинами для тел, образованных вращением профилей известных серий. Исследование проводилось в программном комплексе Ansys Fluent для изотермического ламинарного стационарного течения несжимаемой жидкости с постоянной плотностью в диапазоне скоростей от 0 до $10 \mathrm{~m} / \mathrm{s}$.

DOI: $10.21883 /$ PJTF.2018.08.45963.16828

Показано, что значение силы аэродинамического сопротивления для тела оптимизированной формы ниже аналогичных значений для тел вращения, взятых для сравнения профилей: Су-26 и NASA-0006. По сравнению с величиной для тела вращения профиля NASA-0006 для Су-26 сила аэродинамического сопротивления при скорости потока $10 \mathrm{~m} / \mathrm{s}$ составляет $89.4 \%$, а для оптимизированной формы тела $-89.2 \%$.

Одной из важных и актуальных задач современной аэродинамики является оптимизация формы тела в потоке газа с целью минимизации его аэродинамического сопротивления. Простыми геометрическими формами обладают различные части летательных аппаратов, транспортных средств, инженерных сооружений и конструкций $[1,2]$. Скорости потоков, обтекающих тела, могут изменяться от дозвуковых до гиперзвуковых значений. Данные о параметрах обтекания простых тел широко применяются при анализе аэродинамических характеристик 
более сложных систем, а также при разработке и совершенствовании методов их расчета.

Целью настоящей работы является исследование метода оптимизации геометрических форм тел для уменьшения силы сопротивления в аэродинамическом потоке. Данная цель достигается при моделировании системы тело-поток в программном комплексе путем сравнения величин сил аэродинамического сопротивления для тела оптимизированной формы и тел, образованных путем вращения профилей (NASA-0006, Су-26), которые были выбраны из известных серий (А, В, Р, ЦАГИ, Cy, Як, V, Mynk, Clark, NASA и др.) по наименьшей величине силы аэродинамического сопротивления.

Исследования силы аэродинамического сопротивления тел в потоке газа проводились при условии сохранения объема (массы) для всех сравниваемых объектов. Форма оптимизированного тела определялась по разработанному методу, описанному в [3], основанному на соответствии поверхности оптимизированного тела форме потоковых линий, перпендикулярных эквипотенциальным поверхностям давления [4].

На рис. 1 показано тело оптимизированной по разработанному методу формы для скорости потока $10 \mathrm{~m} / \mathrm{s}$.

Моделирование обтекания тел проводилось для изотермического ламинарного стационарного течения несжимаемой жидкости с постоянной плотностью в программном комплексе Ansys Fluent, объединяющем в себе все необходимые компоненты для исследования аэродинамических характеристик объектов.

Аэродинамический поток описывался уравнениями Навье-Стокса $[5,6]$

$$
\begin{gathered}
\frac{\partial \rho}{\partial t}+\nabla(P \cdot \mathbf{v})=0 \\
\frac{\partial \mathbf{v}}{\partial t}=-\mathbf{v} \cdot(\nabla \mathbf{v})+\nabla T-\frac{1}{\rho} \nabla P+\mathbf{g}
\end{gathered}
$$

где $\mathbf{v}-$ вектор скорости, $\rho-$ плотность, $P-$ давление, $T=2 \mu D-$ тензор напряжений, $\mu-$ коэффициент вязкости, $\mathbf{g}-$ векторное поле массовых сил,

$$
D \equiv D_{i j}=\frac{1}{2}\left(\frac{\partial v_{i}}{\partial x_{j}}+\frac{\partial v_{j}}{\partial x_{i}}\right)
$$

- тензор скоростей деформации.

Поскольку в работе рассматривается исследование аэродинамических характеристик в дозвуковой области в однородном потоке, в

Письма в ЖТФ, 2018, том 44, вып. 8 


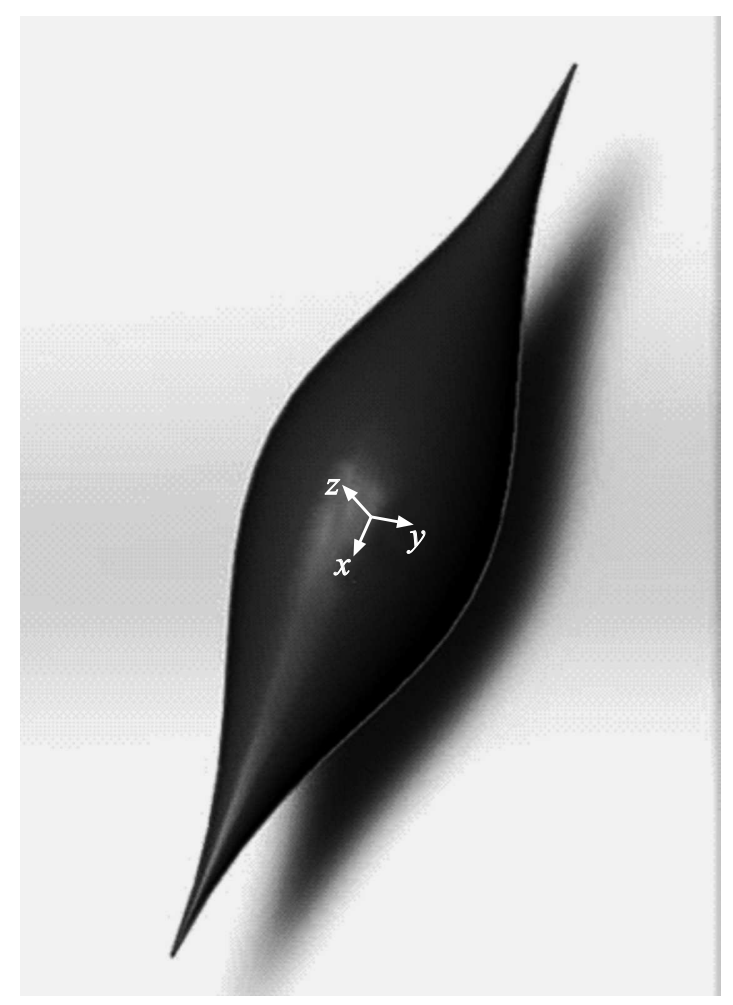

Рис. 1. Тело оптимизированной формы для скорости потока $10 \mathrm{~m} / \mathrm{s}$.

качестве основного решателя Ansys Fluent был выбран „a pressure-based solver called“". В его основе лежат алгоритмы, в которых управляющие уравнения решаются последовательно. Каждая итерация решателя Ansys Fluent основывается на нескольких этапах [7-11]:

- обновление свойств жидкости (таких как вязкость, скорость, удельная теплоемкость и т.д.), основанное на текущем вычислении;

- последовательное решение уравнений импульса, использующее ранее обновленные значения давления и потока массы;

- решение корректировочного уравнения давления с помощью полученных значений скоростей и потоков масс;

Письма в ЖТФ, 2018, том 44, вып. 8 


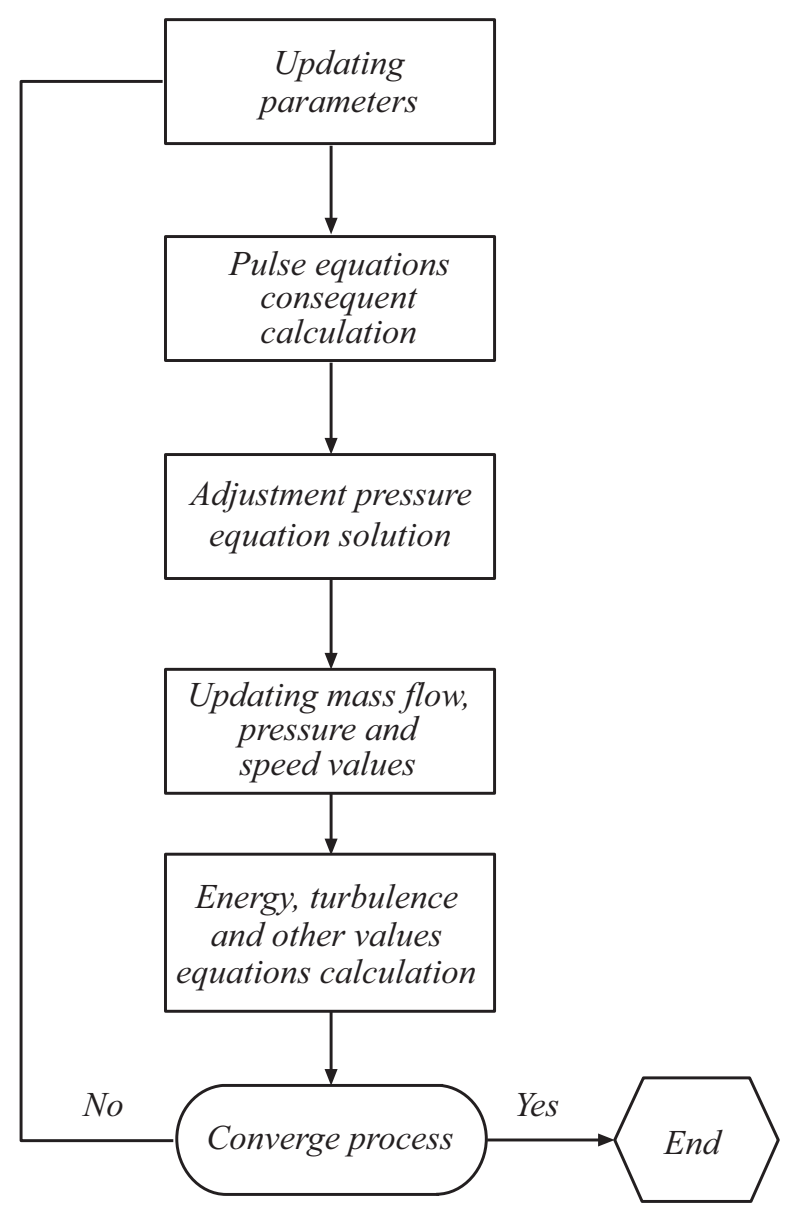

Рис. 2. Блок-схема алгоритма исследования аэродинамических характеристик в дозвуковой области в однородном потоке. 


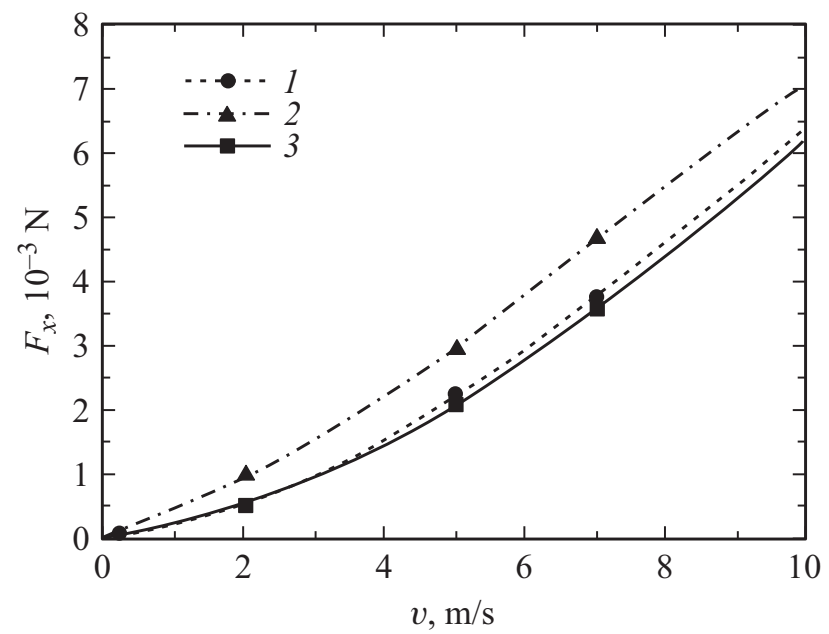

Рис. 3. Зависимость величин сил аэродинамического сопротивления тел вращения профилей Су-26 (1), NASA-0006 (2) и тела оптимизированной формы (3) от скорости аэродинамического потока.

- корректировка величин потока массы, давления и скорости, использующая значения, полученные на предыдущем шаге;

— решение уравнений дополнительных переменных, таких как турбулентные величины, энергия, излучение и т.д.;

- обновление исходного уравнения;

- проверка на сходимость решения уравнения.

На рис. 2 представлена блок-схема алгоритма исследования аэродинамических характеристик в дозвуковой области в однородном потоке.

Анализ величин сил аэродинамического сопротивления $F_{x}$ тел вращения профилей Су-26, NASA-0006 и тела оптимизированной формы для диапазона скоростей от 0 до $10 \mathrm{~m} / \mathrm{s}$ проводился по формуле $[2,12-14]$

$$
F_{x}=\frac{1}{2} \rho v^{2} S c_{x},
$$

где $\rho-$ плотность воздуха, $v-$ скорость набегающего потока, $S$ - площадь поперечного сечения, $c_{x}-$ коэффициент лобового сопротивления.

Результаты сравнения приведены на рис. 3.

3 Письма в ЖТФ, 2018, том 44, вып. 8 
Анализ полученных данных позволяет сделать вывод, что предложенный метод оптимизации во всем указанном диапазоне скоростей потока позволяет уменьшить значение силы аэродинамического сопротивления оптимизированной формы тела по сравнению с аналогичными значениями аэродинамических сопротивлений тел вращения известных серий профилей. По сравнению с величиной силы аэродинамического сопротивления для тела вращения профиля NASA-0006, соответствующей $100 \%$, для Су- 26 она составляет $89.4 \%$, а для оптимизированной формы тела $-89.2 \%$.

\section{Список литературы}

[1] Петров К.П. Аэродинамика тел простейших форм. М.: Факториал,1998. $432 \mathrm{c}$.

[2] Гарбузов В.М., Ермаков А.Л., Кубланов М.С., Ципенко В.Г. Аэромеханика. М.: Транспорт, 2000. $287 \mathrm{c}$.

[3] Палий А.В. Массоперенос и основное уравнение аэродинамики. Таганрог: Изд-во ТТИ ЮФУ, 2012. 192 с.

[4] Палий А.В., Замков Е.Т., Серба П.В. // Изв. ЮФУ. Технические науки. 2012. № 1. C. 192-197.

[5] Perez-Raya I., Kandlikar S.G. // Numerical Heat Transfer B: Fundamentals. 2016. V. 70. N 4. P. 322-339.

[6] Лойцянский Л.Г. Механика жидкости и газа. М.: Дрофа, 2003. 840 с.

[7] Снегирёв А.Ю. Высокопроизводительные вычисления в технической физике. Численное моделирование турбулентных течений. СПб.: Изд-во Политехн. ун-та, 2009. $143 \mathrm{c}$.

[8] Zahariea D. // IOP Conf. Ser.: Mater. Sci. Eng. 2016. V. 161. N 1. P. 012041.

[9] Борисов А.В., Кузнецов С.П., Мамаев И.С., Тененев В.А. // Письма в ЖТФ. 2016. T. 42. B. 17. C. 9-19.

[10] Vetchanin E.V., Mamaev I.S., Tenenev V.A. // Regular Chaotic Dynamics. 2013. V. 18. N 1-2. P. $100-117$.

[11] Аульченко С.М., Каледин В.О., Шпакова Ю.В. // Письма в ЖТФ. 2009. T. 35. B. 3. C. 33-39.

[12] Килин А.А., Ветчанин Е.В. // Нелинейная динамика. 2015. Т. 11. № 4. C. 633-645.

[13] Кольцов С.Н., Галль Л.Н., Галль Н.Р. // Письма в ЖТФ. 2016. Т. 42. В. 5. C. 8-14.

[14] Garimella S., Zhou X., Ouyang Z. // J. Am. Soc. Mass Spectr. 2013. V. 24. N 12. P. $1890-1899$. 